\title{
Aqueous Polyketone Latices Prepared with Water-Insoluble Palladium(II) Catalysts
}

\section{Anke Held, ${ }^{\dagger}$ Ludmila Kolb, ${ }^{\dagger}$ Martin A. Zuideveld, ${ }^{\dagger}$ Ralf Thomann, ${ }^{\dagger}$

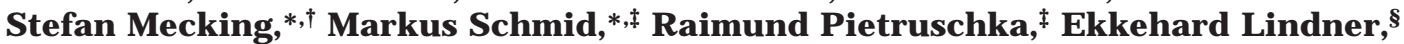 Monther Khanfar, ${ }^{\S}$ and Mahmoud Sunjuk ${ }^{\S}$}

Institut für Makromolekulare Chemie und Freiburger Materialforschungszentrum Albert-L udwigs-Universität Freiburg, Stefan-Meier-Strasse 31, D-79104 Freiburg, Germany; Polymer Research, BASF Aktiengesel Ischaft, D-67056 Ludwigshafen, Germany; and Institut für Anorganische Chemie, Eberhard-Karls-Universität Tübingen, Auf der Morgenstelle 18, D-72076 Tübingen, Germany

\begin{abstract}
Alternating copolymerization of carbon monoxide with ethylene or 1-olefins in aqueous emulsion by water-insoluble palladium(II) complexes is reported. Latices of aliphatic polyketones (1-olefin/CO copolymers and ethylene/undec-10-enoic acid/CO terpolymers), prepared by catalytic polymerization, are described for the first time. An in situ catalyst system $\left[\left\{\mathrm{R}_{2} \mathrm{P}\left(\mathrm{CH}_{2}\right)_{3} \mathrm{PR} \mathrm{R}_{2}\right\} \mathrm{Pd}(\mathrm{OAC})_{2}\right] /$ strong acid $\left(\mathrm{R}=\mathrm{Ph}\right.$ or $\left.\left(\mathrm{CH}_{2}\right)_{13} \mathrm{CH}_{3}\right)$ or well-defined complexes [ $\left.\left\{\mathrm{Ph}_{2} \mathrm{P}\left(\mathrm{CH}_{2}\right)_{3} \mathrm{PPh}_{2}\right\} \mathrm{PdMe}\left(\mathrm{NCCH}_{3}\right)\right]^{+} \mathrm{Y}^{-}$ $\left(\mathrm{Y}^{-}=\left[\mathrm{B}\left\{3,5-\left(\mathrm{F}_{3} \mathrm{C}\right)_{2} \mathrm{C}_{6} \mathrm{H}_{3}\right\}_{4}\right]^{-}\right.$or $\left.\mathrm{SbF}_{6}{ }^{-}\right)$were used in the form of a solution of the palladium(II) complex in miniemulsion droplets of a hydrocarbon dispersed in the continuous aqueous phase. Catalyst activities of up to $5 \times 10^{3} \mathrm{TO} \mathrm{h}^{-1}$ slightly exceed those of nonaqueous polymerizations in methanol with the same catalysts. Polymer molecular weights (GPC vs PMMA standards) are typically $\mathrm{M}_{\mathrm{w}} 2 \times 10^{5}$ (ethylene copolymers) respectively $M_{w} 2 \times 10^{4}$ (1-ol efin copolymers) with $M_{w} / M_{n} 2-4$. The 1-ol efin copolymers exhibit glass transition temperatures of $\mathrm{T}_{\mathrm{g}}=+10$ to $-55^{\circ} \mathrm{C}$, which is in the range desirable for latex applications.
\end{abstract}

\section{Introduction}

Emulsion polymerization of ol efinic monomers, yielding polymer latices, is carried out on a vast scale. ${ }^{1}$ The use of water as a dispersing medium offers a unique combination of features, such as effective transfer of the heat of reaction, effective stabilization of polymer particles by surfactants, and environmental friendliness. In contrast to polymerization in solution or in the bulk, in emulsion polymerization a large portion of polymer can be generated in a given volume of reaction mixture without a significant increase in viscosity. The nontoxicity and nonflammability of water are also advantageous with regard to applications of latices: often film formation upon evaporation of the dispersing medium is a key step. To date, emulsion polymerization is carried out industrially by free radical processes exclusively. Transition-metal-catalyzed coordination polymerization reactions in water have received less attention, as the early-transition-metal catalysts ${ }^{2}$ used commercially for polyolefin production are extremely sensitive to moisture. Carrying out such reactions in aqueous emulsion or suspension is a highly attractive goal, however, as many polymer microstructures are not available by other means than coordinati on polymerization. Because of their lower oxophilicity by comparison to Ziegler catalysts or metallocenes, complexes of late transition metals ${ }^{3}$ are attractive for polymerization in aqueous emulsion or suspension. $4,5,6$

Alternating polyketones obtained by ethylene/propylene/carbon monoxide terpolymerization have been introduced in 1995 as new engineering thermoplastics. ${ }^{7 a}$

* To whom correspondence should be addressed. E-mail: stefan.mecking@makro.uni-freiburg.de; markus.01.schmid@ basf-ag.de

† Albert-Ludwigs-U niversität Freiburg.

‡ BASF AG.

$\S$ E berhard-Karls-Universität Tübingen.
Such materials display excellent chemical resistance and good mechanical wear properties. ${ }^{8}$ The large number of carbonyl groups renders polyketones sensitive to UV light. This behavior can be useful when degradability is desired; however, for most applications lightsensitivity is disadvantageous. In addition, undesired condensation cross-linking at the high temperatures required for processing (e.g., $\mathrm{T}_{\mathrm{m}} \mathrm{ca} .220^{\circ} \mathrm{C}$ for a typical ethylene/propylene/carbon monoxide terpolymer with 6 mol \% propylene) is a drawback. Currently, the future of the commercial engineering thermoplastics is uncertain. ${ }^{7 \mathrm{~b}}$ Nonewithstanding, polyketones possess an interesting property profile, and they are based on carbon monoxide as an exceptionally cheap feedstock. Film formation from aqueous polyketone dispersions could allow for novel applications beyond those explored to date, also circumventing the aforementioned difficulties associated with processing.

In the commercial process, polyketones are prepared in a nonaqueous reaction medium utilizing a cationic $\mathrm{Pd}(\mathrm{II})$ catalyst modified with diphosphine ligands. Copolymerization of ethylene with carbon monoxide has been carried out in aqueous suspension, that is without formation of a polymer latex. Cationic palladium catalysts with water-soluble diphosphine- or al so nitrogenbased bidentate ligands were used. ${ }^{9}$ M ost often, watersoluble diphosphines prepared by sulfonation of 1,3bis(diphenylphosphino)propane (dppp) with $\mathrm{SO}_{3}$ were employed. For aqueous copolymerization of 1-olefins with $\mathrm{CO}$, water-soluble hydroxy-functionalized trialkylsubstituted diphosphines have been used successfully. ${ }^{9 f}$ The aforementioned approaches employ water-soluble ligands, the preparation of which often involves considerable synthetic effort.

We now report on the synthesis and properties of aqueous polyketone latices, using cationic palladium complexes of simple water-insoluble ligands as catalysts. 
Scheme 1. Complexes Employed as Catalyst Precursors and Synthesis of 2
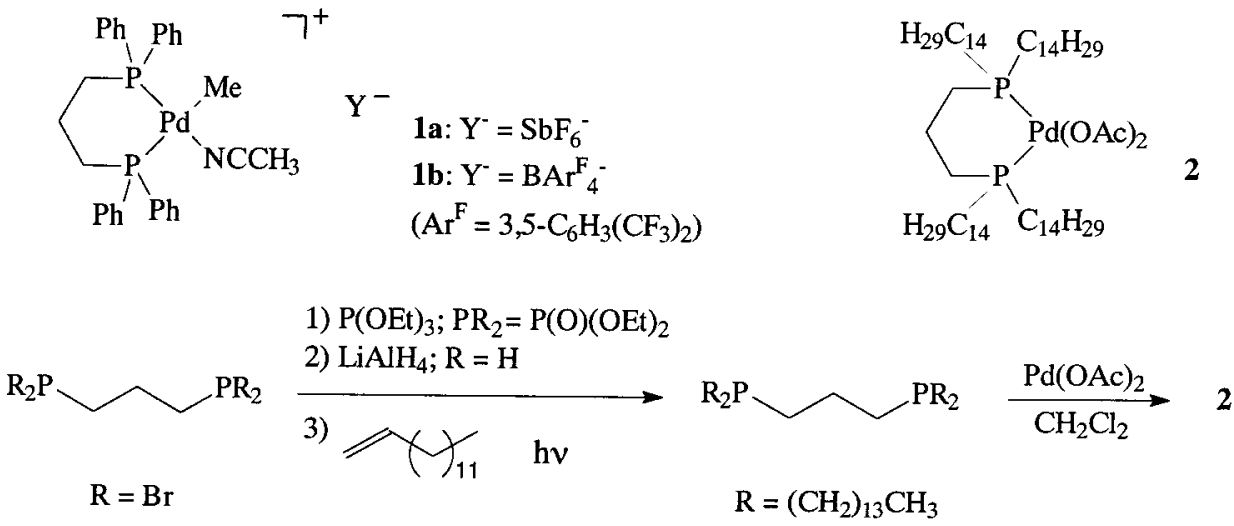

Scheme 2. Catalytically Active Species in Ethylene/CO Copolymerization and Formation from an in Situ Mixture

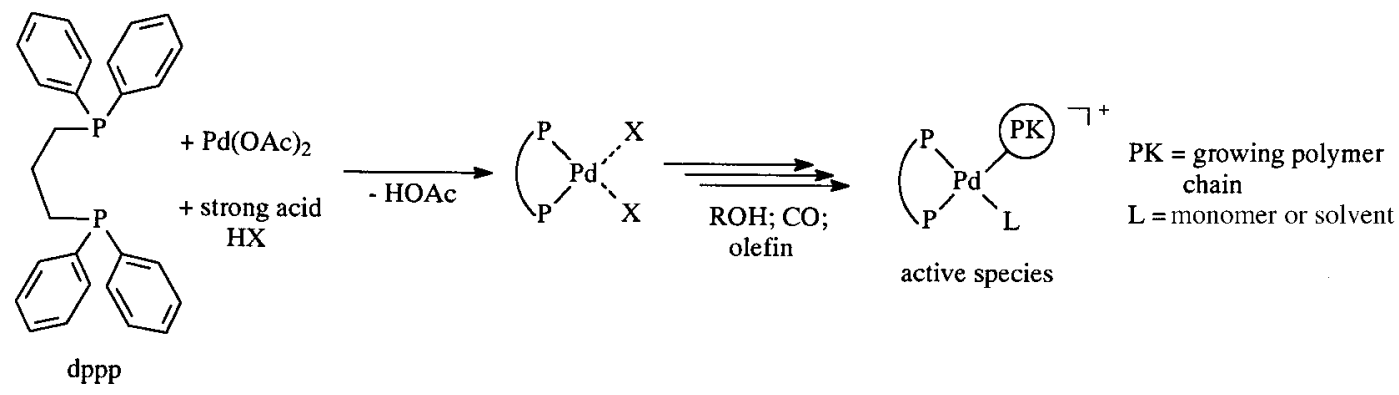

\section{Results and Discussion}

Catalyst Preparation. To achieve a fine dispersion of the catalyst precursor complex, the latter was employed as a solution in small miniemulsion droplets of a liquid hydrocarbon dispersed in a continuous aqueous phase. ${ }^{10}$ Miniemulsions are generally obtained by subjecting a mixture of an apolar organic compound (e.g., an aromatic hydrocarbon), a small amount of a hydrophobe (e.g., hexadecane), surfactant and water to high shear. ${ }^{11}$ The high shear results in the formation of very small droplets, which are stabilized toward Ostwald ripening ${ }^{12}$ to large droplets by the hydrophobe. Different catalyst systems of this type were employed: (a) a miniemulsified solution of a well-defined complex [(dppp)$\left.\mathrm{PdMe}\left(\mathrm{NCCH}_{3}\right)\right]^{+} \mathbf{Y}^{-}$(1a or $\mathbf{1 b}$; cf. Scheme 1) in a small amount of an organic solvent; (b) a solution of a bidentate phosphine ligand $(\mathrm{P} \wedge \mathrm{P})$ and palladium acetate, or a preformed complex $\left[(\mathrm{P} \wedge \mathrm{P}) \mathrm{Pd}(\mathrm{OAc})_{2}\right](\mathbf{2})$, in hydrocarbon/hexadecane miniemulsion droplets combined with a water-soluble strong acid. In ethylene/CO and propylene/CO copolymerization, the hydrocarbon is represented by a small amount of toluene, whereas in the copolymerization of hexene and higher olefins the liquid monomer itself is the hydrocarbon solvent.

Regarding the composition of the in situ systems b, it should be noted that catalyst systems containing palladium acetate, a di phosphine, and a strong acid are well-known. Presumably, they are employed in the commercial nonaqueous suspension-type polyketone process in an alcohol solvent. ${ }^{13}$ The function of the strong acid is most likely displacement of the acetate ligands, to form a more weakly coordinated complex (Scheme 2). There is good evidence that the actual catalytically active species is a cationic palladium complex [(diphosphine) $\mathrm{Pd}(\mathrm{PK})(\mathrm{L})]^{+}$(PK = growing polymer chain, $\mathrm{L}=$ monomer, solvent) which is formed under polymerization conditions. ${ }^{14}$
Ethylene/CO Copolymerization. Results of ethylene/CO copolymerizations with various catalyst systems containing dppp as the bidentate ligand are given in Table 1. Droplet sizes of the catalyst miniemulsions employed in these experiments are approximately 150 $\mathrm{nm} .{ }^{15}$ It should be noted, that the ethylene/CO copolymerization procedure used differs from typical freeradical polymerization of a miniemulsion of a liquid monomer. Gaseous monomers are fed to the reaction mixture continuously, after miniemulsification of the catalyst solution. Thus, polymerization of preformed miniemulsion droplets of a liquid monomer to particles of the same size as the typical feature of "mi niemulsion polymerization" does not apply to this particular case.

Catalytic activities observed in aqueous emulsion employing a miniemulsion of an in situ catalyst (catalyst system b) are comparable to the results of conventional copolymerization in methanol under the same conditions (entry 1 vs 2). This demonstrates that the formation of the active species occurs in an efficient manner also in the aqueous multiphase system employed. As expected, the catalyst is stable in water for hours (entries 3 and 4).

By addition of a solution of $\left[(\mathrm{dppp}) \mathrm{Pd}(\mathrm{OAc})_{2}\right]$ in a small amount of methanol to neat water (containing p-toluenesulfonic acid), the catalyst precursor was precipitated as a solid, without control of the degree of dispersion of the catalyst. By comparison to the afore mentioned miniemulsions of a catalyst solution, this precipitated catalyst displayed a significantly lower activity (entry 5). On one hand, this demonstrates that a high degree of dispersion, as provided with the catalyst miniemulsions, is required for effective polymerization. On the other hand, it is evident that the polymerization can principally also be carried out with a water-insoluble complex without the need of dissolution in an organic medium. ${ }^{16}$ 
Table 1. Ethylene/CO Copolymerizationa

\begin{tabular}{|c|c|c|c|c|c|c|c|c|c|}
\hline \multirow[b]{3}{*}{$\begin{array}{l}\text { entry } \\
\text { no. }\end{array}$} & \multicolumn{4}{|c|}{ reaction conditions } & \multicolumn{5}{|c|}{ results } \\
\hline & \multicolumn{2}{|l|}{ catalyst } & \multirow[b]{2}{*}{$\begin{array}{l}\text { reacn } \\
\text { medium }\end{array}$} & \multirow[b]{2}{*}{$\begin{array}{l}\text { reacn } \\
\text { time/h }\end{array}$} & \multirow{2}{*}{$\begin{array}{l}\text { polym } \\
\text { yield/g }\end{array}$} & \multirow{2}{*}{$\begin{array}{l}\text { productivity/ } \\
\text { (mol(substr) } \\
\times \mathrm{mol}^{\left.(\mathrm{Pd})^{-1}\right)}\end{array}$} & \multirow{2}{*}{ 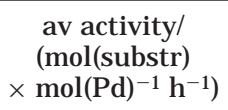 } & \multirow{2}{*}{$\begin{array}{c}M_{n}{ }^{f} \\
\left(M_{w} / M_{n}\right)\end{array}$} & \multirow[b]{2}{*}{$\mathrm{M}_{\mathrm{w}}$} \\
\hline & $\begin{array}{c}\text { organic phase } \\
\text { (miniemulsion droplets) }\end{array}$ & $\begin{array}{l}\text { aqueous phase } \\
\text { (continuous phase) }\end{array}$ & & & & & & & \\
\hline $1^{\mathrm{b}}$ & $\begin{array}{l}\mathrm{Pd}(\mathrm{OAc})_{2} / \mathrm{dppp} \\
\text { (miniemulsion) }\end{array}$ & HOTs (12.5 equiv) & water & 1.5 & 4.3 & 7760 & 5180 & $\begin{array}{l}4.3 \times 10^{4} \\
(3.5)\end{array}$ & $1.5 \times 10^{5}$ \\
\hline 2 & $\begin{array}{l}\mathrm{Pd}(\mathrm{OAc})_{2} / \mathrm{dppp} / \mathrm{HOTs} \text { ( } 12.5 \text { equiv) } \\
\text { (comparative expt in } \mathrm{MeOH} \text { soln) }\end{array}$ & & $\mathrm{MeOH}$ & 2 & 3.4 & 6060 & 3030 & $\begin{array}{l}4.9 \times 10^{4} \\
(4.0)\end{array}$ & $2 \times 10^{5}$ \\
\hline $3^{c, d}$ & $\begin{array}{l}\mathrm{Pd}(\mathrm{OAC})_{2} / \mathrm{dppp} \\
\text { (miniemulsion) }\end{array}$ & HOTs (25 equiv) & water & 2 & 1.04 & 3720 & 1860 & ND & ND \\
\hline $4^{c, d}$ & $\begin{array}{l}\mathrm{Pd}(\mathrm{OAC})_{2} / \mathrm{dppp} \\
\text { (miniemulsion) }\end{array}$ & HOTs ( 25 equiv) & water & 17.5 & 3.9 & 13930 & 800 & ND & ND \\
\hline $5^{e}$ & $\begin{array}{l}\mathrm{Pd}(\mathrm{OAC})_{2} / \mathrm{dppp} \\
\text { (precipitated) }\end{array}$ & HOTs (12.5 equiv) & water & 18 & 0.46 & 820 & 45 & $\begin{array}{l}2 \times 10^{4} \\
(6.0)\end{array}$ & $1.2 \times 10^{5}$ \\
\hline $6^{c}$ & $\begin{array}{l}\text { complex } \mathbf{1 b} \\
\text { (miniemulsion) }\end{array}$ & & water & 2 & 1.73 & 3090 & 1545 & $\begin{array}{l}5.7 \times 10^{4} \\
(4.4)\end{array}$ & $2.5 \times 10^{5}$ \\
\hline 7 & complex $\mathbf{1 b}$ & & $\mathrm{MeOH}$ & 2 & 4.49 & 8000 & 4000 & ND & ND \\
\hline
\end{tabular}

a Reaction conditions: Pd/dppp, 1:1 molar ratio; $\mathrm{n}(\mathrm{Pd}), 20 \mu \mathrm{mol}$; total pressure, 40 bar, ethylene:CO (1:1); organic phase in miniemulsions, toluene $(1.8 \mathrm{~mL})$ and hexadecane $(0.2 \mathrm{~mL}) ; 100 \mathrm{~mL}$ of water; reaction temperature, $70^{\circ} \mathrm{C}$. ND = not determined. HOTs $=\mathrm{p}$-toluenesulfonic acid. ${ }^{b}$ Surfactant: $1.5 \mathrm{~g}=5.2 \mathrm{mmol}$ of SDS. ' Surfactant: $0.75 \mathrm{~g}=2.6 \mathrm{mmol}$ of SDS. ${ }^{\mathrm{d}} \mathrm{n}(\mathrm{Pd}): 10 \mu$ mol; reaction temperature, $70{ }^{\circ} \mathrm{C}$; total pressure, 20 bar, ethylene:CO (1:1). ${ }^{\mathrm{e}}$ Organic phase: methanol (i.e., no miniemulsion); no addition of SDS. ${ }^{\mathrm{f}}$ Determined vs. PMMA standards.

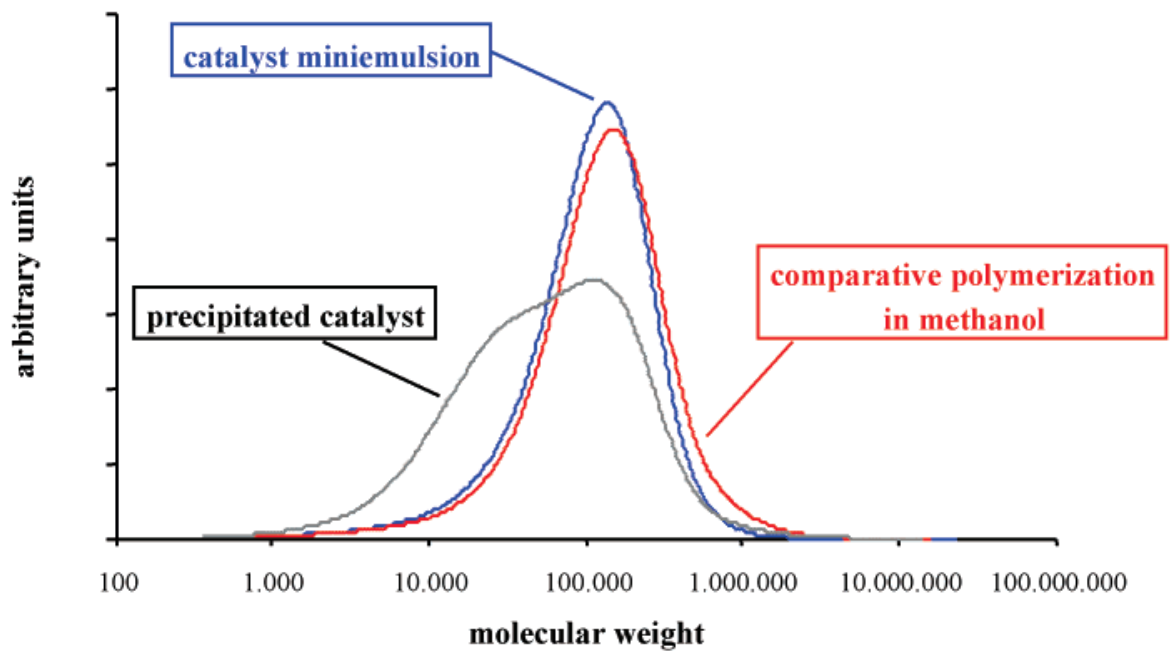

Figure 1. GPC traces of ethylene/CO copolymers obtained with in situ catalyst systems (determined vs PMMA standards).

Regarding the surfactant utilized for the preparation of the miniemulsion, commercially available anionic surfactants, such as sodium dodecyl sulfate (SDS), were found to enable efficient copolymerization. The molecular weights of the ethylene/CO copolymers obtained with the catalyst mi niemulsion and in the comparative experiment in methanol are similar, with $\mathrm{M}_{\mathrm{w}}$ in the range of $1 \times 10^{5}$ to $2 \times 10^{5}$ (Figure 1 and Table 1 ; molecular weights determined by GPC vs PMMA standards). By comparison, the polyketone obtained with the precipitated catalyst possesses a broader molecular weight distribution and a lower $M_{n}$. The stability of the resulting ethylene/CO copolymer dispersions was found to be insufficient, and in the aforementioned experiments, the polyketone was largely precipitated by the end of the polymerization reactions.

Stable dispersions can be obtained, however, by utilizing undecenoic acid as a termonomer. In a typical experiment, a solution of $20 \mu \mathrm{mol}\left[(\mathrm{dppp}) \mathrm{Pd}(\mathrm{OAc})_{2}\right]$ in $3.5 \mathrm{~mL}$ of undec-10-enoic acid was miniemulsified in 100 $\mathrm{mL}$ of water by ultrasonification, employing SDS as a surfactant. Polymerization at $70{ }^{\circ} \mathrm{C}$ and $40 \mathrm{bar}$ of combined ethylene and carbon monoxide pressure (1:1 mixture) with 12 equiv of p-toluene sulfonic acid dis- solved in the aqueous phase afforded a stable latex (reaction time $2 \mathrm{~h}$ ). A typical TEM image is shown in Figure 2. For the sample shown, particle sizes are in the range of ca. 30-200 nm. Partial film formation during the preparation of the samples for TEM is evident. ${ }^{13} \mathrm{C}$ NMR spectra of the terpolymer in $1,1,1,3,3,3-$ hexafluoropropan-2-ol solution confirm the incorporation of the undecenoic acid monomer in the polyketone (ca. $10 \mathrm{wt} \%$, corresponding to ca. $3 \mathrm{~mol} \%$ vs incorporated ethylene). As expected, only isolated undecenoic acid-derived units $\left(-\mathrm{CH}_{2} \mathrm{CH}_{2} \mathrm{C}(=\mathrm{O}) \mathrm{CH}_{2} \mathrm{CHRC}(=\mathrm{O}) \mathrm{CH}_{2}\right.$ $\mathrm{CH}_{2}-$ with $\left.\mathrm{R}=\left(\mathrm{CH}_{2}\right)_{8} \mathrm{COOH}\right)$ are detected. A typical terpolymer possesses a molecular weight of $M_{w}=7 \times$ $10^{4}$ at $M_{w} / M_{n}=2.5$. In the latices, hydrophilic carboxylic acid moieties covalently bound to the particle surface contribute to stabilization. ${ }^{1}$ In the aforementi oned terpolymerizations, ca. $5-10 \%$ of the undecenoic acid termonomer are converted. Interestingly, in a comparative experiment in methanol as a nonaqueous reaction medium, employing the 3-fold amount of undecenoic acid termonomer in solution $(10 \mathrm{~mL}$ of undecenoic acid, corresponding to $0.5 \mathrm{~mol} \mathrm{~L}^{-1}$ ) under otherwise identical conditions, no incorporation of the termonomer could be detected. The high local concentration of the liquid 

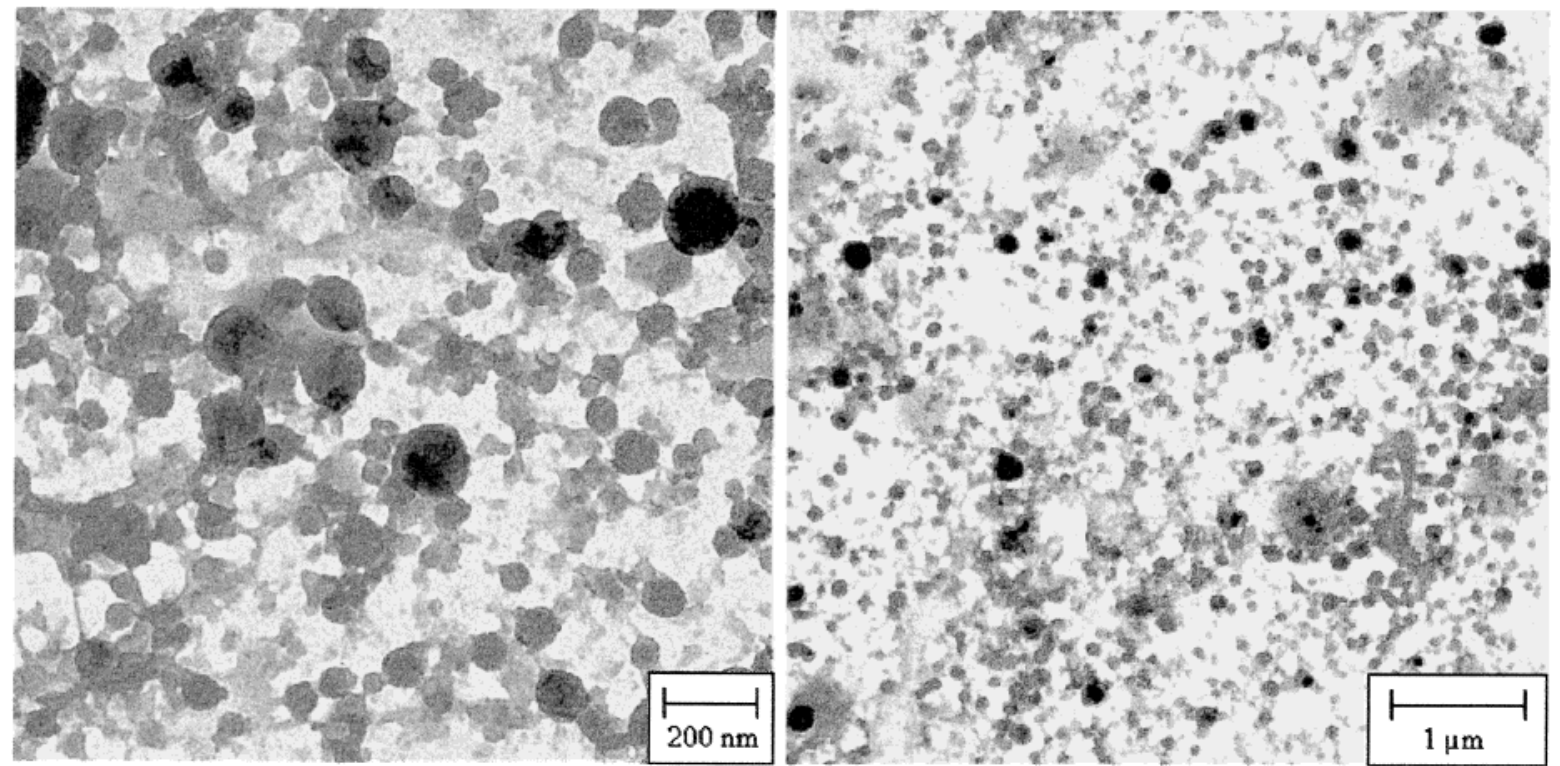

Figure 2. TEM images of an ethylene/undecenoic acid/carbon monoxide terpolymer latex.

comonomer in droplets during the aqueous polymerization enhances incorporation; that is, polymerization in the compartimented aqueous system is beneficial for comonomer incorporation.

The aforementioned in situ catalyst system is advantageous for industrial applications due to its simplicity. However, for in situ catalysts in general and in particular for the multiphase systems employed in this work, catalyst activation can be influenced by a number of (mostly unknown) parameters. For this reason, complexes of type $\mathbf{1}^{17}$ were employed as a well-defined, single component catalyst precursor. Because of the lipophilic $\mathrm{BArF}_{4}{ }^{-}$counterion $\left(\mathrm{ArF}^{\mathrm{F}}=3,5-\mathrm{C}_{6} \mathrm{H}_{3}\left(\mathrm{CF}_{3}\right)_{2}\right),{ }^{18}$ $\mathbf{1 b}$ is highly soluble also in apolar solvents, and it can be employed in the toluene/hexadecane miniemulsion system. Complex la with a hexafluoroantimonate counterion is insufficiently soluble in toluene, and requires the use of a toluene/methylene chloride mixture as a solvent. As methylene chloride has a significant solubility in water, in order to perform experiments under controlled conditions it would be necessary to saturate the aqueous phase with the chlorinated solvent prior to the experiment, which is undesirable. Nonetheless, it can be noted that polymerization can al so be carried out effectively employing miniemulsions of a solution of $\mathbf{1 a}$ in toluene/methylene chloride mixtures.

Activity of $\mathbf{1 b}$ in a comparative experiment in methanol (entry 7) is similar to activities observed in the aforementioned (aqueous and nonaqueous) in situ system, confirming an efficient formation of the active catalyst in the in situ systems. Employing $\mathbf{1 b}$ in miniemulsion (entry 6) good activities are observed again. Unexpectedly, by comparison to aqueous polymerization with the miniemulsified in situ catalyst, polymer yields observed with the well-defined catalyst precursor in entry 6 are somewhat lower. This is apparently due to the beneficial effect of toluenesulfonic acid, present as a component of the in situ system in excess with respect to palladium(II): Carrying out a polymerization with the isolated complex $\mathbf{1 b}$ in the presence of added toluenesulfonic acid (12.5 equiv) under otherwise identical conditions as in entry 6, a 3-fold increase of polymer yield was observed. This activity is similar to polymerization with the in situ catalyst. Presumably the pres- ence of excess strong acid stabilizes the catalyst during polymerization. ${ }^{14}$ The molecular weight of the polymer is comparable to the material obtained with the in situ catalyst. In comparative aqueous polymerization with freshly precipitated solid complexes $\mathbf{1}$, activities are again lower $(<20 \%)$ by comparison to the miniemulsion system. Overall, the results with the well-defined complexes $\mathbf{1}$ are similar to the aforementioned findings with the in situ system. This confirms the well-behaved nature of the in situ systems, regardless of their multiphase nature.

1-Olefin/CO Copolymerization. In view of latex applications, a control of the glass transition temperature is of particular importance. By employment of 1-ol efin comonomers, the thermal properties of polyketones can be varied over a wide range by appropriate choice of the ol efin. ${ }^{19}$

It is known that diphosphine ligands bearing exclusively alkyl substituents on the phosphorus atoms (by comparison to the phenyl groups in, e.g., dppp) are particularly suitable for the copolymerization of 1-ol efins with CO. ${ }^{9 f}$ Therefore, the apolar complex $\mathbf{2}$ in combination with 10 equiv of trifluoroacetic acid was employed. As alluded to, with hexene and higher 1-olefins the liquid monomer itself can be employed as the organic phase for preparation of the catalyst miniemulsions, eliminating the need of a small amount of an additional organic solvent (Table 2, entries 2-5). Hereby the amount of volatile organic compounds can be reduced, as demonstrated for the ring-opening polymerization of cyclopentene with ruthenium complexes. ${ }^{20}$ After sonification, stable miniemulsions of about $200 \mathrm{~nm}$ droplet size with a broad size distribution were obtained. The selection of a suitable emulsifier is crucial on one hand for the stability of the emulsion and on the other hand for catalyst activity. With Lumiten IRA, a 2-sulfosuccinic acid ethylhexyl ester, very stable catalyst emulsions are formed. However, with this emulsifier no catalytic activity was observed, which may be caused by the chelating capability of the diacid ester (entry 3 ). This drawback is overcome by employing SDS, and immediate use of the catalyst miniemulsion for polymerization. F urther enhancement in catalyst performance was achieved by adding hydrophobic al cohol s like hexa- 
Table 2. 1-Olefin CO Copolymerizationa

\begin{tabular}{|c|c|c|c|c|c|c|c|c|c|}
\hline \multirow[b]{3}{*}{$\begin{array}{l}\text { entry } \\
\text { no. }\end{array}$} & \multicolumn{3}{|c|}{ reaction conditions } & \multicolumn{6}{|c|}{ results } \\
\hline & \multicolumn{2}{|l|}{ catalyst } & \multirow[b]{2}{*}{$\begin{array}{l}\text { reacn } \\
\text { time/h }\end{array}$} & \multirow[b]{2}{*}{$\begin{array}{l}\text { solids } \\
\text { content/\% }\end{array}$} & \multirow{2}{*}{ 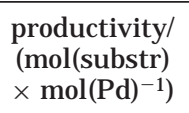 } & \multirow{2}{*}{ 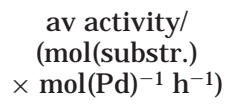 } & \multirow[b]{2}{*}{$M_{w}$} & \multirow[b]{2}{*}{$M_{w} / M_{n}$} & \multirow[b]{2}{*}{$\begin{array}{l}\text { thermal } \\
\text { anal. } /{ }^{\circ} \mathrm{C}\end{array}$} \\
\hline & $\begin{array}{c}\text { organic phase } \\
\text { (miniemulsion droplets) }\end{array}$ & emulsifier & & & & & & & \\
\hline $1^{\mathrm{b}}$ & $\begin{array}{l}\text { complex } \mathbf{2} / \text { toluene/hexadecane/ } \\
\text { propene/ } / \mathrm{CF}_{3} \mathrm{COOH}\end{array}$ & SDS & 5 & 5 & 15200 & 3040 & $3.2 \times 10^{4}$ & 2.5 & $\begin{array}{r}10\left(T_{g}\right) \\
150\left(T_{m}\right)\end{array}$ \\
\hline $\begin{array}{l}2 \\
3\end{array}$ & $\begin{array}{l}\text { complex } 2 / 1 \text {-hexene/ } / \mathrm{CF}_{3} \mathrm{COOH} \\
\text { complex } 2 / 1 \text {-hexene/ } / \mathrm{CF}_{3} \mathrm{COOH}\end{array}$ & $\begin{array}{l}\text { SDS } \\
\text { Lumiten IRA }\end{array}$ & $\begin{array}{l}10 \\
10\end{array}$ & $\begin{array}{c}8 \\
\text { trace }\end{array}$ & 15600 & 1560 & $2.5 \times 10^{4}$ & 3.2 & $-25\left(T_{g}\right)$ \\
\hline 4 & complex 2/1-decene/ $\mathrm{CF}_{3} \mathrm{COOH}$ & SDS & 10 & 10 & 13200 & 1320 & $1.6 \times 10^{4}$ & 2.8 & $-55\left(\mathrm{~T}_{\mathrm{g}}\right)$ \\
\hline $5^{c}$ & $\begin{array}{l}\text { complex 2/1-octadecene/ } \\
\text { hexadecanol/CF }{ }_{3} \mathrm{COOH}\end{array}$ & SDS & 12 & 12 & 9800 & 820 & $1.8 \times 10^{4}$ & 3.0 & $40\left(\mathrm{~T}_{\mathrm{m}}\right)$ \\
\hline
\end{tabular}

a Reaction conditions: $10 \mu \mathrm{mol}$ of complex 2; 10 equiv of $\mathrm{CF}_{3} \mathrm{COOH} ; 30 \mathrm{~g}$ of ol efin; $100 \mathrm{~mL}$ of water; $0.3 \mathrm{~g}$ of emulsifier; total pressure, $60 \mathrm{bar}$; reaction temperature, $80^{\circ} \mathrm{C}$. ${ }^{\mathrm{b}} 10 \mathrm{~mL}$ of toluene, $0.3 \mathrm{~g}$ of $\mathrm{n}$-hexadecane. ${ }^{\mathrm{c}} 2 \mathrm{~g}$ of 1-hexadecanol added.

decanol to the ol efinic monomer (entry 5). Alcohols are known to promote the activation reaction of dicationic palladium complexes. ${ }^{21}$

As a product of polymerization, stable polyketone latices are obtained without formation of coagulum. Solids contents were up to $12 \%$ in the experiments given in Table 2. Light-scattering analyses reveal that the latices particle size is roughly similar to the droplet size of the monomer miniemulsions employed. This implies that no extensive coalescence or formation of new particles or droplets occurs during polymerization. The yields of $20-30 \%$ with respect to the olefinic monomer are moderate. U pon drying of the dispersions at roomtemperature, polyketone films were formed. IR spectra feature typical CO bands around $1700 \mathrm{~cm}^{-1}$. The molecular weights of the 1-olefin/CO copolymers are in the range $\mathrm{M}_{\mathrm{w}}=(1-3) \times 10^{4}$, at reasonably narrow molecular weight distributions. As anticipated, the glass transition temperature ranges from +10 (propene/CO) to $-55^{\circ} \mathrm{C}$ (1-decene/CO). The 1-octadecene/CO copolymer exhibits a strong melting peak of about $40{ }^{\circ} \mathrm{C}$ due to side chain crystallization.

\section{Summary and Conclusions}

Readily accessible nonwater-soluble ligands can be applied to aqueous ol efin/CO copolymerization, employing catalyst miniemulsions. At the same time, stable aqueous dispersions of alternating al i phatic polyketones can be obtained. Approximately the same catalyst activities are observed in aqueous polymerization as in comparative nonaqueous polymerizations in organic solvents. Activities in aqueous polymerization of simple in situ systems are equal to those of a well-defined complex under similar conditions, demonstrating that activation of the in situ system occurs effectively in these multiphase miniemulsion systems. Latices of 1-olefin/CO copolymers with glass transition temperatures in the range +10 to $-55^{\circ} \mathrm{C}$, which is desirable for typical latex applications, are accessible.

\section{Experimental Section}

Materials and General Considerations. Ethylene (99.8\%) and carbon monoxide (99.8\%) supplied by Gerling and $\mathrm{Holz}$ were used without further purification. 1-Hexene, 1-decene, and 1-octadecene were purchased from Aldrich. The p.a. grade organic solvents and deionized water were degassed prior to use.

NMR spectra were recorded on a Bruker ARX 300 instrument $\left({ }^{1} \mathrm{H}, 300 \mathrm{MHz} ;{ }^{13} \mathrm{C}, 75 \mathrm{MHz}\right)$, or on a Bruker DRX-250 spectrometer $\left({ }^{1} \mathrm{H}, 250.13 \mathrm{MHz} ;{ }^{13} \mathrm{C}, 62.90 \mathrm{MHz} ;{ }^{31} \mathrm{P}, 101.26\right.$ $\mathrm{MHz}) .{ }^{1} \mathrm{H} N M R$ chemical shifts were referred to TMS as an internal standard. ${ }^{13} \mathrm{C}\left\{{ }^{1} \mathrm{H}\right\}$ NMR chemical shifts were calibrated against the deuterated solvent multiplet and referenced to TMS. ${ }^{31} \mathrm{P}\left\{{ }^{1} \mathrm{H}\right\} \mathrm{NMR}$ chemical shifts were measured relative to external $85 \% \mathrm{H}_{3} \mathrm{PO}_{4}$ with downfield values being taken as positive. ${ }^{13} \mathrm{C}$ NMR spectra of ethylene/undecenoic acid/carbon monoxide terpolymers were obtained in 1,1,1,3,3,3-hexafluoro2 -propanol as a solvent with an inverse gated pulse sequence. The resonances of a small amount of added $C_{6} D_{6}$ served as a lock and for calibration vs TMS. Elemental analyses were carried out using a Elementar Vario EL analyzer. FAB-MS were obtained on a Finnigan 711A (8 kV), modified by AMD. Differential scanning calorimetry (DSC) was performed on a Perkin-EImer DSC 7 or on a Pyris 1 DSC at a heating rate of $10 \mathrm{~K} / \mathrm{min}$. DSC data reported are second heats. Gel permeation chromatography of ethylene/CO co- and terpolymers was performed in 1,1,1,3,3,3-hexafluoro-2-propanol at $40{ }^{\circ} \mathrm{C}$ with PL HFIP gel columns against PMMA standards. GPC of 1-olefin/CO copol ymers was carried out in THF . Dynamic light scattering on dispersions was performed on a Malvern particle sizer. TEM investigations were carried out on a LEO 912 Omega apparatus using an acceleration voltage of $120 \mathrm{kV}$. Samples were prepared by applying a drop of the latex to a carbon-coated grid. Samples were not stained.

Synthesis of Catalyst Precursor Complexes. Complexes $\mathbf{1 a}, \mathbf{1} \mathbf{b},{ }^{17}$ and $\mathbf{2}^{9 f}$ were prepared similar to literature proce dures. Analytical data for $\mathbf{2}$ (yellowish oil obtained in $90 \%$ yield) follow. MS (FAB, NBA, $\left.50{ }^{\circ} \mathrm{C}\right): \mathrm{m} / \mathrm{z} 1058[\mathrm{M}-\mathrm{OAC}]^{+}$, 998 [M - $2 \mathrm{OAC}^{+}$. Anal. Calcd for $\mathrm{C}_{63} \mathrm{H}_{128} \mathrm{O}_{4} \mathrm{P}_{2} \mathrm{Pd}$ (1118.1): $\mathrm{C}$, 67.68; $\mathrm{H}, 11.54$. Found $\mathrm{C}, 67.47 ; \mathrm{H}, 11.21 \% .{ }^{31} \mathrm{P}\left\{{ }^{1} \mathrm{H}\right\} \mathrm{NMR}$ $\left(101.26 \mathrm{MHz} \mathrm{CDCl}_{3}, 22^{\circ} \mathrm{C}\right): \delta=14.5 .{ }^{1} \mathrm{H} \mathrm{NMR}(250.13 \mathrm{MHz}$ $\left.\mathrm{CDCl}_{3}, 22^{\circ} \mathrm{C}\right): \delta=0.83\left(\mathrm{t},{ }^{3} \mathrm{HH}=6.5 \mathrm{~Hz}, 12 \mathrm{H} ; \mathrm{CH}_{2} \mathrm{CH}_{3}\right), 1.18-$ $1.82\left(\mathrm{~m}, 12 \mathrm{OH} ; \mathrm{CH}_{2}\right), 1.95\left(\mathrm{~s}, 6 \mathrm{H} ; \mathrm{CH}_{3} \mathrm{COO}\right) .{ }^{13} \mathrm{C}\left\{{ }^{1} \mathrm{H}\right\} \mathrm{NMR}$ $\left(62.90 \mathrm{MHz} \mathrm{CDCl}_{3}, 22^{\circ} \mathrm{C}\right): \delta=14.2\left(\mathrm{~s}, \mathrm{CH}_{3} \mathrm{CH}_{2}\right), 19.6\left(\mathrm{~s}, \mathrm{CH}_{2-}\right.$ $\mathrm{COO}), 25.4\left(\mathrm{~m}, \mathrm{CH}_{2} \mathrm{PC}_{2}\right), 29.1-29.8\left(\mathrm{~m}, \mathrm{CH}_{2}\right), 31.4\left(\mathrm{~m},\left(\mathrm{CH}_{2}\right)_{2-}\right.$ $P C), 32.6\left(\mathrm{~s}, \mathrm{CH}_{2} \mathrm{CH}_{2} \mathrm{CH}_{3}\right), 176.9\left(\mathrm{~s}, \mathrm{CH}_{3} \mathrm{COO}\right)$.

Polymerization Procedure. Polymerization was carried out in a mechanically stirred $250 \mathrm{~mL}$ pressure reactor equipped with a heating/cooling jacket, the temperature being controlled automatically by means of a sensor dipping into the reaction mixture. The total volume of the added liquid phase (water and/or organic solvent) amounted to $100 \mathrm{~mL}$. For catalyst systems of type $b$, the palladium salt and the bidentate phosphine ligand were dissolved separately in small amounts of toluene/hexadecane and combined to yield a yellow solution. For catalyst type a, complex $\mathbf{1 a}$ or $\mathbf{1 b}$ was dissolved $(\mathbf{1} \mathbf{a}, \mathbf{1 : 1}$ mixture of methylene chloride and toluene; $\mathbf{1 b}$, neat toluene), and some hexadecane was added. The catalyst solution was added to an aqueous solution of the surfactant. Ultrasonification afforded a miniemulsion (Bandelin HD2200 with a KE 76 tip, operated at $120 \mathrm{~W}$ ), which was transferred to the polymerization reactor. Optionally, toluenesulfonic acid was then added as an aqueous solution. The reactor was flushed and pressurized with a 1:1 ethylene/CO mixture, while rapidly heating to the specified temperature under vigorous stirring (1000 rpm). After the specified reaction time, the reaction was stopped by cooling and releasing the gas pressure. In experiments yielding precipitated polymers, these were isolated, washed with water and methanol, and dried in a vacuum. In experiments yielding a polymer latex, the latter was filtered 
through a funnel with glass wool prior to further workup and analysis. For determination of the solids content, the latex was added to an excess of methanol. The precipitated polymers were isolated, washed with methanol, and dried in a vacuum. 1-olefin/CO copolymerization was carried out with $\mathbf{2}$ in a 300 $\mathrm{mL}$ reactor under otherwise similar conditions.

${ }^{13} \mathrm{C}\left\{{ }^{1} \mathrm{H}\right\} N M R$ of ethylene/undecenoic acid/carbon monoxide copolymer (75.4 M Hz, 1,1,1,3,3,3-hexafluoro-2-propanol/ $\left.\mathrm{C}_{6} \mathrm{D}_{6}\right)$ : $\delta=217.1\left(\mathrm{CH}_{2} \mathrm{C}(=\mathrm{O}) \mathrm{CHR}\right), 212.8\left(\mathrm{CH}_{2} \mathrm{C}(=\mathrm{O}) \mathrm{CH}_{2}\right), 179.7$ $(\mathrm{COOH}), 46.8\left(\mathrm{C}(=\mathrm{O}) \mathrm{CHRCH}_{2} \mathrm{C}(=\mathrm{O})\right), 43.4\left(\mathrm{C}(=\mathrm{O}) \mathrm{CHRCH}_{2-}\right.$ $\mathrm{C}(=\mathrm{O})), 35.6\left(\mathrm{C}(=\mathrm{O}) \mathrm{CH}_{2} \mathrm{CH}_{2} \mathrm{C}(=\mathrm{O})\right), 33.5\left(\mathrm{CH}_{2} \mathrm{COOH}\right), 31.4$ $\left(\mathrm{CH}_{2}\left(\mathrm{CH}_{2}\right)_{7} \mathrm{COOH}\right), 29.2-28.7\left(\mathrm{CH}_{2} \mathrm{CH}_{2} \mathrm{CH}_{2} \mathrm{CH}_{2} \mathrm{CH}_{2} \mathrm{CH}_{2} \mathrm{COOH}\right)$, $26.9\left(\mathrm{CH}_{2} \mathrm{CH}_{2} \mathrm{COOH}\right), 24.6\left(\mathrm{CH}_{2}\left(\mathrm{CH}_{2}\right)_{6} \mathrm{COOH}\right)$.

Acknowledgment. We thank the Deutsche Forschungsgemeinschaft for financial support (SF B 428 and Graduiertenkolleg-stipend to A.H). M.A.Z. is grateful to the Al exander von Humboldt-F oundation for a research fellowship. S.M. is in debt to the F onds der Chemischen Industrie for financial support. The Freiburg group thanks A. Rossel for construction of high pressure equipment. The authors thank M. Chowdhry, M. Kristen and $\mathrm{H}$. Weiss (BASF) for fruitful discussions and J . Adrian for GPC measurements.

\section{References and Notes}

(1) (a) Emulsion Polymerization and Emulsion Polymers; Lovell, P. A., El-Aasser, M. S., Eds.; Wiley: Chichester; 1997. (b) Wässrige Polymerdispersionen; Distler, D., Ed.; VCH: Weinheim, Germany, 1999. (c) Lagaly, G.; Schulz, O.; Zimehl, R. Dispersionen und Emulsionen; Steinkopff: Darmstadt, Germany, 1997; (d) Fitch, R. M. Polymer Colloids: a Compre hensive Introduction; Academic Press: San Diego, CA, 1997.

(2) (a) Ziegler Catalysts; Fink, G., Mülhaupt, R., Brintzinger, $H$. H., Eds.; Springer: Berlin, 1995. (b) Brintzinger, H. H.; Fischer, D.; Mülhaupt, R.; Rieger, B.; Waymouth, R. Angew. Chem. 1995, 107, 1255-1283; Angew. Chem., Int. Ed. Engl. 1995, 34, 1143-1170. (c) Britovsek, G. J . P.; Gibson, V. C.; Wass, D. F. Angew. Chem. 1999, 111, 448-468; Angew. Chem., Int. Ed. Engl. 1999, 38, 428-447. (d) Kaminsky, W.; Arndt, M. Adv. Polym. Sci. 1997, 127, 143-187.

(3) Recent reviews on late-transition-metal catalysts for ol efin polymerization: (a) Mecking, S. Coord. Chem. Rev. 2000, 203 , 325-351. (b) Ittel, S. D.; J ohnson, L. K.; Brookhart, M. Chem. Rev. 2000, 100, 1169-1204. (c) Mecking, S. Angew. Chem. 2001, 113, 550-557; Angew. Chem., Int. Ed. 2001, 40, 534540.

(4) Leading references on aqueous polymerization of butadiene: (a) Rinehart, R. E.; Smith, H. P.; Witt, H. S.; Romeyn, H. J Am. Chem. Soc. 1961, 83, 4864-4865. (b) Canale, A. J.; Hewett, W. A.; Shryne, T. M.; Youngman, E. A. Chem. Ind. 1962, 1054-1055. (c) Henderson, J. N.; Donbar, K. W.; Barbour, J . J .; Bell, A. J . (Goodyear) U.S. Pat. 4429085 , 1984. Vinyl-type polymerization of cyclobutene: (d) Natta, G.; Dall'Asta, G.; Motroni, G. Polym. Lett. 1964, 2, 349-351. ROMP of norbornenes: (e) Rinehart, R. E.J . Polym. Sci., Part C 1969, 27, 7-25. (f) Novak, B. M.; Grubbs, R. H. J. Am. Chem. Soc. 1988, 110, 7542-7543. (g) Feast, W. J .; Harrison, D. B. J . Mol. Catal. 1991, 65, 63-72. (h) Lu, S.-Y.; Quayle, P.; Booth, C.; Yeates, S. F.; Padget, J. C. Polym. Int. 1993, 32, 1-4. (j) Lynn, D. M.; Mohr, B.; Grubbs, R. H. J . Am. Chem. Soc. 1998, 120, 1627-1628. (k) Mohr, B.; Lynn, D. M.; Grubbs, R. H. Organometallics 1996, 15, 4317-4325. Ethylene polymerization: (I) Held, A.; Bauers, F. M.; Mecking, S. Chem. Commun. 2000, 301-302. (m) Bauers, F. M. Mecking, S. Macromol ecules 2001, 34, 1165-1171. (n) Bauers, F. M.; Mecking, S. Angew. Chem. 2001, 113, 3112-3115 Angew. Chem. Int. Ed. 2001, 40, 3020-3022. (o) Tomov, A.; Broyer, J.-P.; Spitz, R. Macromol. Symp. 2000, 150, 53-58. (p) Soula, R.; Novat, C.; Tomov, A.; Spitz, R.; Claverie, J.; Drujon, X.; Malinge, J .; Saudemont, T. Macromol ecules 2001 ,
34, 2022-2026. Alternating ol efin/CO copolymerization: ref 9.

(5) Review on aqueous catalytic polymerization of ol efins: Mecking, S.; Held, A.; Bauers, F. M. Angew. Chem. 2002, 114, 564582, Angew. Chem. Int. Ed. 2002, 41, 544-561.

(6) Aqueous polymerization of styrene to syndiotactic polystyrene by a titanium complex has recently been described. The activity of the early-transition-metal catalyst in the aqueous polymerization is assumed to be due to an encapsulation (cf. refs $4 \mathrm{c}$ and 16 ) of the catalyst in the polymer, partially formed in a prepolymerization in the absence of water: Manders, B.; Sciandrone, L.; Hauck, G.; Kristen, M. O. Angew. Chem. 2001, 113, 4139-41; Angew. Chem. Int. Ed. 2001, 40, 40064007.

(7) (a) Alperowicz, N. Chem. Week 1995, J uly 2, 22. (b) Chem. Eng. News 2000, 78 (Feb. 28, no. 9), 16.

(8) Also, the ketone moieties in the aliphatic polymer backbone of polyketones allow for a variety of further functionalization reactions: Sen, A. Adv. Polym. Sci. 1986, 73/ 74, 125-144.

(9) (a) J iang, Z.; Sen, A. Macromolecules 1994, 27, 7215-7216. (b) Verspui, G.: Papadogianakis, G.: Sheldon, R. A. Chem. Commun. 1998, 401-402. (c) Bianchini, C.; Man Lee, H.; Meli, A.; Moneti, S.; Patinec, V.; Petrucci, G.; Vizza, F. Macromolecules 1999, 32, 3859-3866. (d) Verspui, G.; Feiken, J .; Papadogianakis, G.; Sheldon, R. A. J . Mol. Catal. 1999, 146, 299-307. (e) Verspui, G.; Schanssema, F.; Sheldon, R. A. Angew. Chem. 2000, 112, 825-827; Angew. Chem., Int. Ed. 2000, 39, 804-806. (f) Lindner, E.; Schmid, M.; Wald, J .; Queisser, J . A.; Geprägs, M.; Wegner, P.; Nachtigal, C. J . Organomet. Chem. 2000, 602, 173-187. (g) Also see: Reppe, W.; Magin, A. US Pat. 2577 208, 1948.

(10) A similar approach has been employed for the synthesis of polyethylene dispersions: (a) refs $4 n$ and $4 p$ and polynorbornene dispersions. (b) Claverie, J . P.; Viala, S.; Maurel, V.; Novata, C. Macromolecules 2001, 34, 382-388.

(11) (a) Sudol, E. S.; El-Aasser, M. S. In ref 1a, pp 699-722. (b) Landfester, K.; Macromol. Rapid Commun. 2001, 22, 896936.

(12) Evans, D. F.; Wennerstroem, H. The Colloidal Domain: where Physics, Chemistry, Biology, and Technol ogy meet, 2nd ed.; VCH: Weinheim, Germany, 1999, p 66.

(13) (a) Drent, E. (Shell) EP-B 121965, 1984. (b) Drent, E.; van Broekhoven, J . A. M.; Doyle, M. J . J . Organomet. Chem. 1991 $417,235-251$

(14) Reviews on olefin/CO copolymerization: (a) Drent, E.; Budzelaar, P. H. M. Chem. Rev. 1996, 96, 663-681. (b) Sen, A. Acc. Chem. Res. 1993, 26, 303-10. (c) ref 19b.

(15) Determined by dynamic light scattering on a Malvern particle sizer. The necessity of extensively diluting the turbid emulsion for this analysis can result in deviations from the original state of the liquid/liquid (mini)emulsion. Therefore, these numbers should be regarded as a rough estimate.

(16) For an investigation of ethylene homopolymerization to amorphous polymer by a water-insoluble cationic palladium diimine complex, cf. Held, A.; Mecking, S. Chem.-Eur. J. 2000, 6, 4623-4629.

(17) (a) Dekker, G. P. C. M.; Elsevier, C. J .; Vrieze, K.; Van Leeuwen, P. W. N. M. Organometallics 1992, 11, 1598-1603. (b) Toth, I.; Elsevier, C. J . J. Am. Chem. Soc. 1993, 115, 10388-10389. (c) Mecking, S.; J ohnson, L. K.; Wang, L.; Brookhart, M. J. Am. Chem. Soc. 1998, 120, 888-899.

(18) (a) Brookhart, M.; Grant, B. A.; Vol pe, A. F., J r. Organome tallics 1992, 11, 3920-3922. (b) Nishida, H.; Takada, N.; Yoshimura, M.; Sonoda, T.; Kobayashi, H. Bull. Chem. Soc. J pn. 1984, 57, 2600-2604.

(19) (a) Abu-Surrah, A. S.; Wursche, R.; Rieger, B. Macromol Chem. Phys. 1997, 198, 1197-1208. (b) Abu-Surrah, A. S.; Rieger, B. Topics Catal. 1999, 7, 165-177.

(20) Kühn, I.; Mohr, B.; Durant, Y.; Schwab, P.; Leyrer, R. (BASF) DE-A 19859191, 2000.

(21) (a) J iang, Z.; Dahlen, G. M.; Houseknecht, K.; Sen, A. Macromolecules, 1992, 25, 2999-3001. (b) Zhao, A. X.; Chien, J. C. W. J. Polym. Sci., Part A: Polym. Chem. 1992, 30, 2735-2747. (c) Ref 13b. 